\title{
Early predictive factors of single dose methotrexate outcome in patients with ectopic pregnancy
}

\author{
Jérémy Brunello ${ }^{1}$ Paul Guerby ${ }^{1,2} \cdot$ Chloé Cartoux $^{3}$ - Alexandre Yazigi ${ }^{1}$ - Martin Baujat ${ }^{1}$. Olivier Parant ${ }^{1,2,4}$. \\ Christophe Vayssière ${ }^{1,2,4} \cdot$ Elodie Chantalat $^{2,5} \cdot$ Fabien Vidal $^{1,2}$
}

Received: 19 May 2019 / Accepted: 8 July 2019 / Published online: 27 July 2019

(c) Springer-Verlag GmbH Germany, part of Springer Nature 2019

Dear editor,

We read with great interest the comment of Levin et al. regarding our article recently published in Archives of Gynecology and Obstetrics [1]. In their letter, the authors suggest that the dosage we used for single dose methotrexate (MTX) therapy $\left(1 \mathrm{mg} / \mathrm{kg}\right.$, versus $50 \mathrm{mg} / \mathrm{m}^{2}$ of body surface area in the protocol by Stowall et al. [2]) may explain the relatively low success rate we observed $(54.5 \%$ following a single injection). However, high-quality data comparing the efficacy of single dose MTX treatment according to MTX dosage are still lacking. Hence, recent French guidelines have recommended the use of both dosages [3].

In a recent retrospective study, Levin et al. tried to identify early markers of single dose MTX success. The authors concluded that the initial $24 \mathrm{~h}$ increase in $\beta \mathrm{hCG}$ and the percentage change in $\beta$ hCG from day 1 to day 4 were significant prognostic factors for treatment outcome [4]. Nevertheless, their true performances in predicting treatment success were quite low. Indeed, $\beta$ hCG change between day 1 and day 4 displayed an area under curve (AUC) of 0.66 . In contrast, AUC was 0.826 in our study. Furthermore, it is unclear whether baseline $\beta$ hCG level was included in their logistic regression model while it has been identified as a strong prognosis factor in many studies $[1,5]$.

Fabien Vidal

vidal.fabien@chu-toulouse.fr

1 CHU Toulouse, Pôle de Gynécologie Obstétrique, Hôpital Paule de Viguier, 31059 Toulouse, France

2 Université de Toulouse III, UMR1027, 31073 Toulouse, France

3 Department of Obstetrics and Gynecology, CHU Saint-Pierre, Gaillon, La Réunion, France

4 Inserm, UMR1027, 31073 Toulouse, France

5 CHU Toulouse, Service de Chirurgie Gynécologique, 31059 Toulouse, France
We agree that identification of earlier predictors of single dose MTX success is of tremendous importance. However, their implementation in routine practice is probably even more important. To date, available literature does not support the use of early $\beta \mathrm{hCG}$ kinetics to plan post-treatment follow-up, except for patients displaying extreme changes. Further, larger and prospective studies are thus required to fully determine the clinical usefulness of such parameters.

\section{Compliance with ethical standards}

Conflict of interest The authors declare that they have no conflict of interest.

\section{References}

1. Brunello J, Guerby P, Cartoux C, Yazigi A, Baujat M, Parant O et al (2019) Can early $\beta$ hCG change and baseline progesterone level predict treatment outcome in patients receiving single dose Methotrexate protocol for tubal ectopic pregnancy? Arch Gynecol Obstet 299(3):741-745

2. Stovall TG, Ling FW, Gray LA (1991) Single-dose methotrexate for treatment of ectopic pregnancy. Obstet Gynecol 77(5):754-757

3. Marret H, Fauconnier A, Dubernard G, Misme H, Lagarce L, Lesavre $\mathrm{M}$ et al (2016) Overview and guidelines of off-label use of methotrexate in ectopic pregnancy: report by CNGOF. Eur J Obstet Gynecol Reprod Biol 205:105-109

4. Levin G, Dior U, Shushan A, Gilad R, Benshushan A, Rottenstreich A (2019) Early prediction of methotrexate treatment success by 24-hour pretreatment hCG increment and day 1-4 hCG ratio. Reproductive Bio Med Online. https://doi.org/10.1016/j. rbmo.2019.02.005

5. Cohen A, Zakar L, Gil Y, Amer-Alshiek J, Bibi G, Almog B et al (2014) Methotrexate success rates in progressing ectopic pregnancies: a reappraisal. Am J Obstet Gynecol. 211(2):128.e1-5

Publisher's Note Springer Nature remains neutral with regard to jurisdictional claims in published maps and institutional affiliations. 